\title{
Morphological and molecular descriptions of Moniliformis saudi sp. n. (Acanthocephala: Moniliformidae) from the desert hedgehog, Paraechinus aethiopicus (Ehrenberg) in Saudi Arabia, with a key to species and notes on histopathology
}

\author{
Omar M. Amin ${ }^{1}$, Richard A. Heckmann², Osama Mohammed ${ }^{3}$ and R. Paul Evans ${ }^{4}$ \\ ${ }^{1}$ Institute of Parasitic Diseases, Scottsdale, Arizona, USA; \\ ${ }^{2}$ Department of Biology, Brigham Young University, Provo, Utah, USA; \\ ${ }^{3}$ KSU Mammals Research Chair, Department of Zoology, College of Science, King Saud University, Saudi Arabia; \\ ${ }^{4}$ Department of Microbiology and Molecular Biology, Brigham Young University, Provo, Utah
}

\begin{abstract}
A new acanthocepohalan species, Moniliformis saudi sp. n. is described from the desert hedgehog, Paraechinus aethiopicus (Ehrenberg), in central Saudi Arabia. Fourteen other valid species of Moniliformis Travassos, 1915 are recognised. The new species of Moniliformis is distinguished by having a small proboscis (315-520 $\mu \mathrm{m}$ long and 130-208 $\mu \mathrm{m}$ wide) with two apical pores, 14 rows of 8 hooks each and small hooks, thre largest being 25-31 $\mu \mathrm{m}$ long anteriorly. Distinguishing features are incorporated in a dichotomous key to the species of Moniliformis. The description is augmented by scanning electron microscopical (SEM) observation and DNA analysis of nuclear (18S rRNA) and mitochondrial (cytochrome oxidase subunit 1; coxl) gene sequences. Attached worms cause extensive damage to the immediate area of attachment in the host intestine. This includes tissue necrosis and blood loss due to damage to capillary beds. Worms also obstruct essential absorbing surfaces.
\end{abstract}

Keywords: molecular analysis, host-parasite interface, comparisons, morfology, taxonomy

Surveys of mammals and their parasitic fauna in Central Saudi Arabia (CSA) were conducted on regular monthly intervals. Both host and parasite faunas of CSA and the Kingdom are poorly documented. The host, the desert hedgehog, Paraechinus aethiopicus (Ehrenberg), is one of the smallest hedgehogs in the world. It is common in Saudi Arabia and other Middle Eastern and African countries (Harrison and Bates 1991) but only Moniliformis moniliformis (Bremser, 1811) has been reported from its intestinal track in Egypt (Nelson and Ward 1966) and in Algeria (Khaldi et al. 2012). The present report documents a new acanthocephalan species from this host in Saudi Arabia, a land virgin for new discoveries including new parasitic taxa.

\section{MATERIALS AND METHODS}

Desert hedgehogs (Paraechinus aethiopicus) were collected by live traps monthly between August 2014 and March 2015 most-

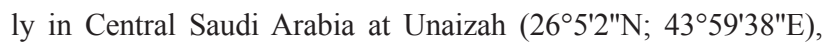
Al Qassim Province. They were first overdosed with anesthetic agents before dissection. Acanthocephalans were placed in wa- ter overnight and then in $70 \%$ ethanol to process for microscopy, scanning electron microscopical (SEM) and DNA analyses, and in neutral buffered formalin for histopathological sectioning. The total number of hedgehogs examined was 89 animals (50 males and 39 females) weighing $355 \pm 92 \mathrm{~g}$. Infected hedgehogs (18 males and 12 females) weighed 166-495 g (mean $304 \pm 80 \mathrm{~g}$ ).

For microscopical examination, specimens in $70 \%$ ethanol were punctured with a fine needle, then stained in Mayer's acid carmine, destained in $4 \%$ hydrochloric acid in $70 \%$ ethanol, dehydrated in ascending concentrations of ethanol ( $24 \mathrm{~h}$ each), and cleared in 100\% xylene and then in 50\% Canada balsam and 50\% xylene ( $24 \mathrm{~h}$ each). Whole worms were then mounted in Canada balsam. Measurements are in micrometres, unless otherwise noted; the range is followed by the mean values between parentheses. Width measurements represent maximum width. Trunk length does not include proboscis, neck or bursa.

For SEM studies, specimens previously fixed in $70 \%$ ethanol were placed in critical-point drying baskets and dehydrated using ethanol series of $95 \%$ and $100 \%$ for at least 10 min per soak followed by critical point drying (Lee 1992). Samples were mounted on SEM sample mounts, gold coated and observed with a scan- 
Table 1. GenBank accession numbers for taxa used in the phylogenetic analyses

\begin{tabular}{|c|c|c|c|}
\hline \multirow[t]{2}{*}{ Family } & \multirow[t]{2}{*}{ Species } & \multicolumn{2}{|c|}{ GenBank accession number } \\
\hline & & $\operatorname{cox} 1$ & $18 \mathrm{~S}$ rDNA \\
\hline \multirow[t]{2}{*}{ Gigantorhynchidae } & Mediorhynchus africans Amin, Evans, Heckmann et El-Naggar, 2013 & KC261351 & KC261353 \\
\hline & Mediorhynchus gallinarum (Bhalerao, 1937) & KC261352 & KC261354 \\
\hline \multirow[t]{2}{*}{ Moniliformidae } & Moniliformis moniliformis (Bremser, 1811) & AF416998 & Z19562 \\
\hline & Moniliformis saudi sp. n. & KU206783 & KU206782 \\
\hline \multirow[t]{3}{*}{ Oligacanthorhynchidae } & Oncicola sp. & AF417000 & AF064818 \\
\hline & Macracanthorhynchus ingens (von Linstow, 1879) & AF16997 & AF001844 \\
\hline & Oligacanthorhychus tortuosa (Leidy, 1850) & AF416999 & AF064817 \\
\hline Brachionidae & Brachionus plicatlis (Müller, 1786) & AY218090 & AY218118 \\
\hline
\end{tabular}

Species and sequences from the present study in bold.

ning electron microscope (XL30 ESEMFEG; FEI, Hillsboro, Oregon, USA). Digital images of the structures were obtained using digital imaging software connected to a computer.

For histological sections, infected host tissue was fixed in neutral $10 \%$ buffered formalin and after dehydration and blocking, the specimens were processed using standard methods (Bancroft and Gamble 2001, Kiernan 2002). The paraffin blocked tissue was sectioned at 4-6 $\mu \mathrm{m}$, placed on glass slides and stained with hematoxylin and eosin. Additional sections were stained with Mallory's trichrome (Galigher and Kozloff 1971). The prepared glass slides were viewed with an LSM laser (Carl Zeiss, Thornwood, New York, USA) equipped compound light microscope with representative pictures taken at varying magnifications with a digital camera.

Total DNA was extracted from six specimens (three males and three females) that were preserved in $70 \%$ ethanol. Each of the individuals originated from a different hedgehog individual. Entire specimens were soaked in $500 \mu \mathrm{l}$ of ATL buffer (tissue lysis buffer) for $10 \mathrm{~min}$ prior to tissue digestion and subsequent DNA purification using a Qiagen DNAeasy Blood and Tissue kit (Qiagen Inc., Valencia, California, USA). Samples were macerated by scissors and the protocol followed as outlined by the manufacturer. DNA yields were $65-374 \mathrm{ng} / \mu \mathrm{l}$ in $200 \mu \mathrm{l}$ of elution buffer and of high molecular weight (fragments greater than $15 \mathrm{~kb}$ ) as determined by $0.7 \%$ agarose gel electrophoresis.

A $664 \mathrm{bp}$ fragment of the mitochondrial cytochrome oxidase subunit 1 gene (coxl) was PCR amplified using the primers 5'-AGTTCTAATCATAA(R)GATAT(Y)GG-3' and 5'-TAAACTTCAGGGTGACCAAAAAATCA-3' (Folmer et al. 1994). Primers used for the amplification of a $1685 \mathrm{bp}$ fragment of the nuclear 18S rRNA gene were 5'-AGATTAAGCCATGCATGCGTAAG-3' and 5'-TGATCCTTCTGCAGGTTCACCTAC-3' (Near et al. 1998). Reaction cocktails were $12.5 \mu 1$ in volume and included the following reagents: DNA template $(\sim 150 \mathrm{ng})$, nuclease free water $(2.25 \mu \mathrm{l})$, oligonucleotide primers (10 pmol each), and Promega GoTaq ${ }^{\circledR}$ Green Master Mix $(6.25 \mu 1)$ (Promega Corporation, Madison, Wisconsin, USA). The thermal profile began with an initial denaturation step of $95^{\circ} \mathrm{C}$ for $2 \mathrm{~min}$ to activate the enzyme, followed by 35 cycles of $95^{\circ} \mathrm{C}$ for $30 \mathrm{~s}, 55^{\circ} \mathrm{C}$ for $30 \mathrm{~s}$, and $72{ }^{\circ} \mathrm{C}$ for $90 \mathrm{~s}$, and concluded by a rapid cool down to $4{ }^{\circ} \mathrm{C}$. Successful amplifications were verified qualitatively by viewing PCR products under ultraviolet radiation following electrophoresis through $1.0 \%$ agarose gels. Millipore MultiScreen ${ }_{\mu 96}$ filter plates (Fisher Scientific, Pittsburg, Pennsylvania, USA) were used to purify PCR products following the manufacturer's recommended protocol.

Cycle sequencing reactions were performed using the ABI Big Dye Terminator protocol (Applied Biosystems, Foster City, California, USA). Reaction cocktails were $10.5 \mu 1$ in volume, and were mixed using the following reagent amounts: purified PCR product $(\sim 150 \mathrm{ng})$, nuclease free water $(2.75 \mu \mathrm{l}), 5 \times$ Tris buffer $(1.75 \mu \mathrm{l})$, primer $(6 \mathrm{pmol})$, and dye terminator reaction mix $(0.5 \mu 1)$. Both DNA strands were sequenced using the same primers that were used to amplify the genes via PCR. The thermal profile for the sequencing reactions consisted of 25 cycles of $96^{\circ} \mathrm{C}$ for $10 \mathrm{~s}, 50^{\circ} \mathrm{C}$ for $5 \mathrm{~s}, 60^{\circ} \mathrm{C}$ for $4 \mathrm{~min}$, followed by a rapid cool down to $4{ }^{\circ} \mathrm{C}$. All sequencing was carried out on an ABI 3730xl automated sequencer in the DNA Sequencing Center at Brigham Young University. Sequence data for cox 1 and 18S rDNA generated from this study are available from GenBank under accession numbers KU206782 and KU206783.

Sequences (Table 1) were initially aligned with Sequencher v. 5.2 (Gene Codes Corp.) and subsequently corrected by eye. Tree reconstructions were carried out using maximum parsimony (MP) and maximum-likelihood (ML) methods on each of the individual genes and a concatenated single alignment. Concatenation was implemented using Geneious (v7.1.4; Kearse et. al. 2012). Bootstrapping of MP, distance-based reconstructions entailed 1000 replications, with random additions of taxa, on informative sites. The PAUP*4.2a program package (Swofford 2003) was used for MP reconstructions. The appropriate model of sequence evolution was selected using jModelTest 0.1.1 (Posada 2008) as implemented in PhyML v. 3.0 (Guindon and Gascuel 2003). ML phylogenies were generated using TreeFinder (version of October 2008; Jobb 2008), and nodal support was estimated by performing 1000 bootstrap replicates. The $18 \mathrm{~S}$ rDNA and cox 1 sequences from Brachionus plicatus Müller, 1786, a rotiferan (Brachionidae), were included in the analyses as outgroups.

For maximum-likelihood (ML) and maximum parsimony (MP) analyses, representative coxl and 18S rDNA sequences from the class Archiachanthocephala were obtained from GenBank (Table 1). Within this class, Gigantorhynchidae, Moniliformidae and Oligacanthrorhynchidae are each the sole family in their respective orders. The Moniliformidae are a particularly DNA sequence depauperate family with published sequence available from a single species, Moniliformis moniliformis. This study provides a second set of sequences of members of the family Moniliformidae. 


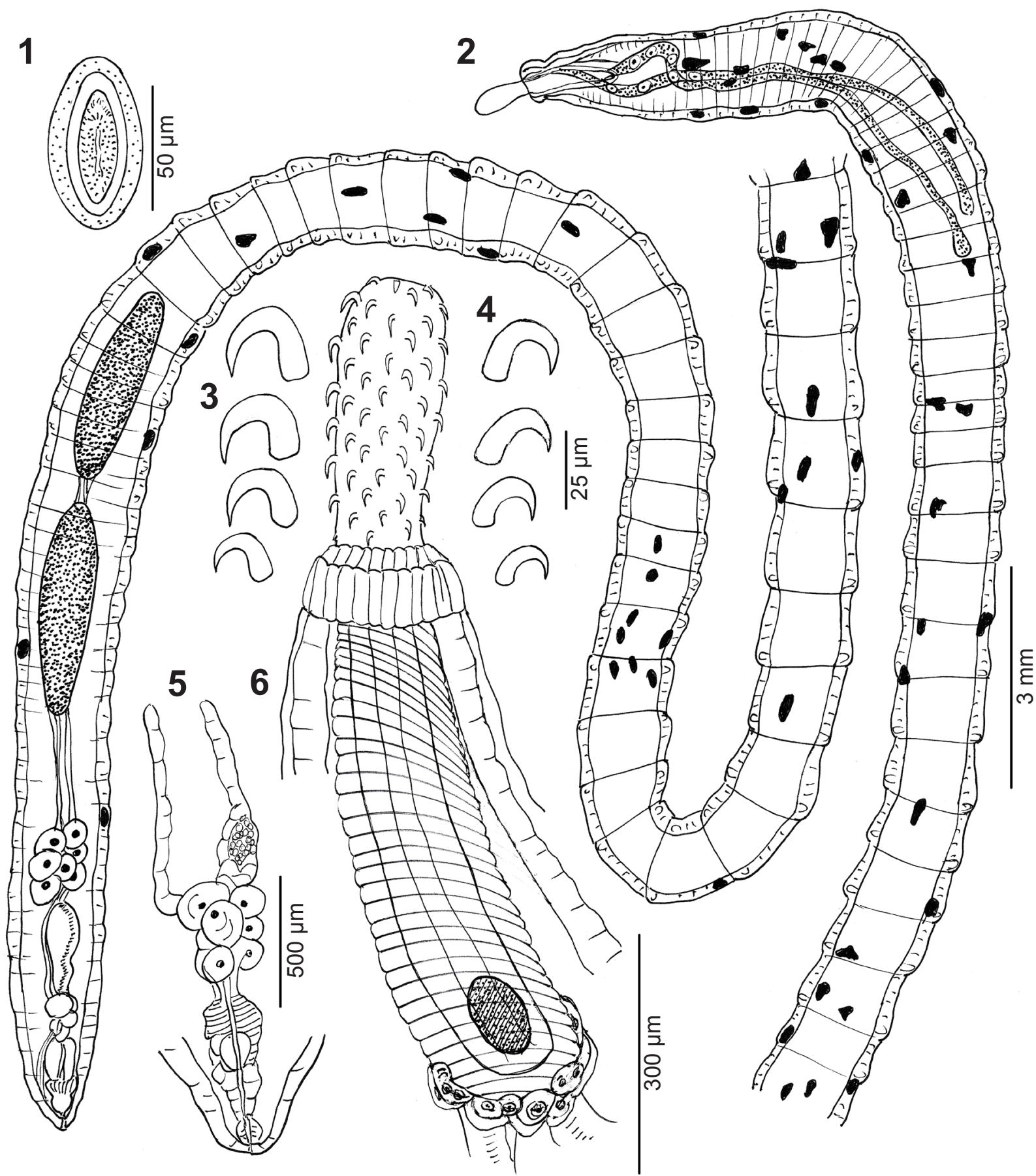

Figs. 1-6. Sexually mature specimens of Moniliformis saudi sp. n. from the desert hedgehog, Paraechinus aethiopicus (Ehrenberg) in Saudi Arabia. Fig. 1. An egg with concentric shells and smooth surface. Fig. 2. Holotype male. Note the number and location of giant nuclei in the body wall, the near contiguous, post-equatorial ovoid testes, and extent and location of pseudosegmentation. Figs. 3, 4. Ventral hooks nos. 1, 2, 4, 8 (Fig. 3) and smaller dorsal hooks (Fig. 4) of the same specimen in Figs. 1, 2. Fig. 5. The short and robust reproductive system of the allotype female. Fig. 6 . The anterior end of the same specimen showing the size proportion of the proboscis and the receptacle, the anterior trunk festoons, and the nucleated cells at the posterior end of the receptacle.

\section{RESULTS}

Specimens of a new species of Moniliformis Travassos, 1915 were collected from 30 of 89 examined desert hedgehogs in Saudi Arabia examined monthly between August 2014 and March 2015. A few of the 30 infected hedge hogs were also concurrently infected with two species of nematodes and one of species tapeworms that will be reported elsewhere.

\section{Moniliformis saudi sp. n.}

ZooBank number for species:

urn:Isid:zoobank.org:act:31BDF782-0BE9-4487-BFB9-CF6D46995AC4

Description. General. Moniliformida: Moniliformidae. With characters of the genus Moniliformis. Medium-sized worms with very small proboscis size compared to trunk 

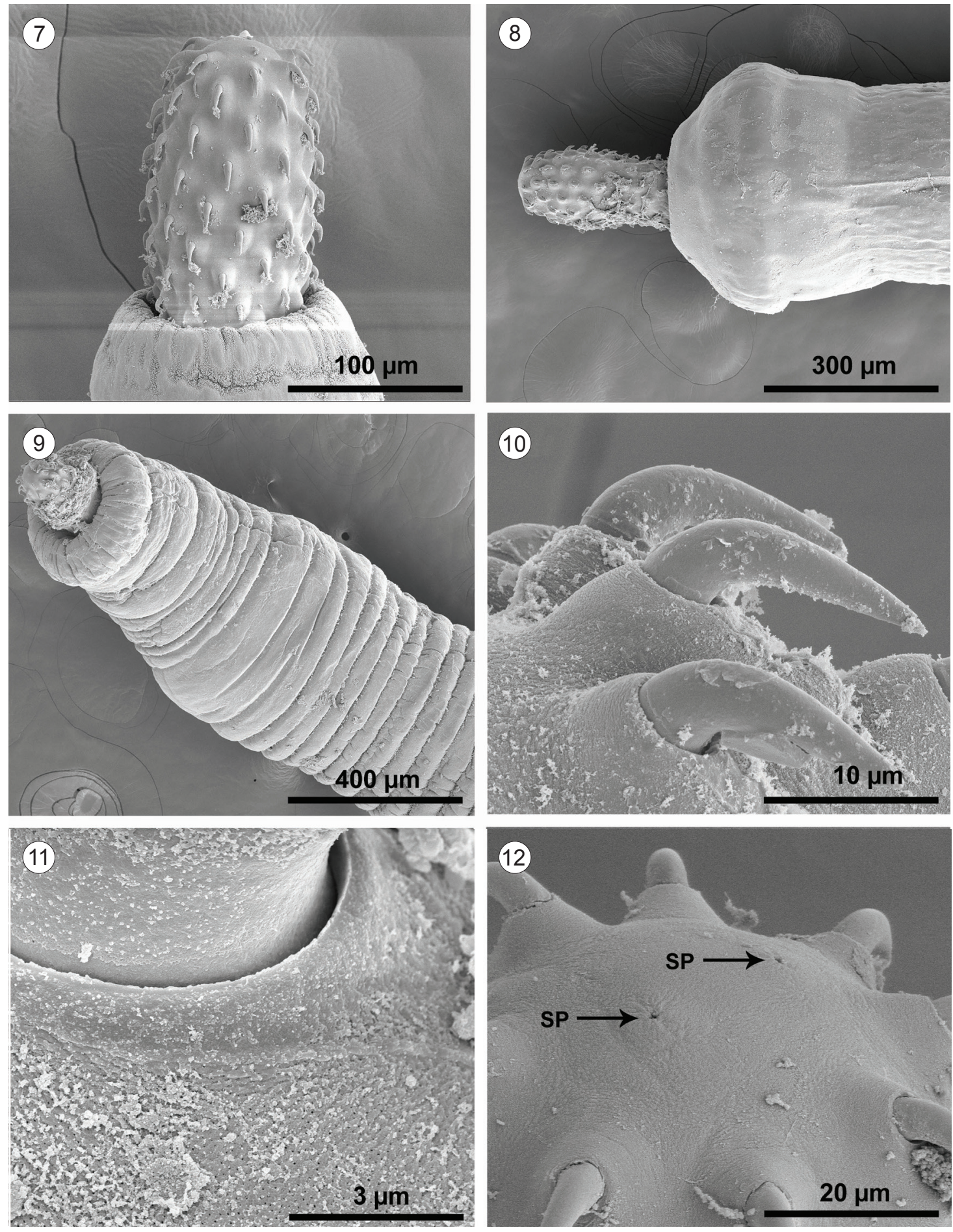

Figs. 7-12. SEM micrographs of adults of Moniliformis saudi sp. n. from the desert hedgehog, Paraechinus aethiopicus (Ehrenberg) in Saudi Arabia. Fig. 7. The proboscis of an adult male specimen; note the anterior trunk girdle of plates. Fig. 8. Anterior portion of another specimen; note the expanded conical shape of the anterior trunk. Fig. 9. Another perspective of the anterior end of a specimen showing a prominent anterior trunk girdle and close pseudosegmentation. Fig. 10. A lateral view of anterior proboscis hooks. Fig. 11. The base on an anterior hooks showing the presence of micropores on adjacent proboscis surface. Fig. 12. The apical end of a proboscis showing two sensory pores (SP).

size. Pseudosegmented except anteriorly and posteriorly beginning at level of male reproductive system (Fig. 2). Pseudosegmentation unremarkable in small worms but conspicuously taeniate in larger worms (Figs. 23, 24). Pseudosegments largest at middle or posterior of trunk, gradually getting smaller anteriorly. Shared structures larg- er in females than in males. Anterior trunk cone-shaped then sharply tapering towards anterior prominent festooned girdle of vertical sections, especially in specimens with partially retracted proboscis (Figs. 2, 6-9). Body wall aspinose with 11-43 (mean 19) lateral, 2-12 (mean 9) dorsal and 4-17 (mean 10) ventral mostly stellate giant nuclei; 

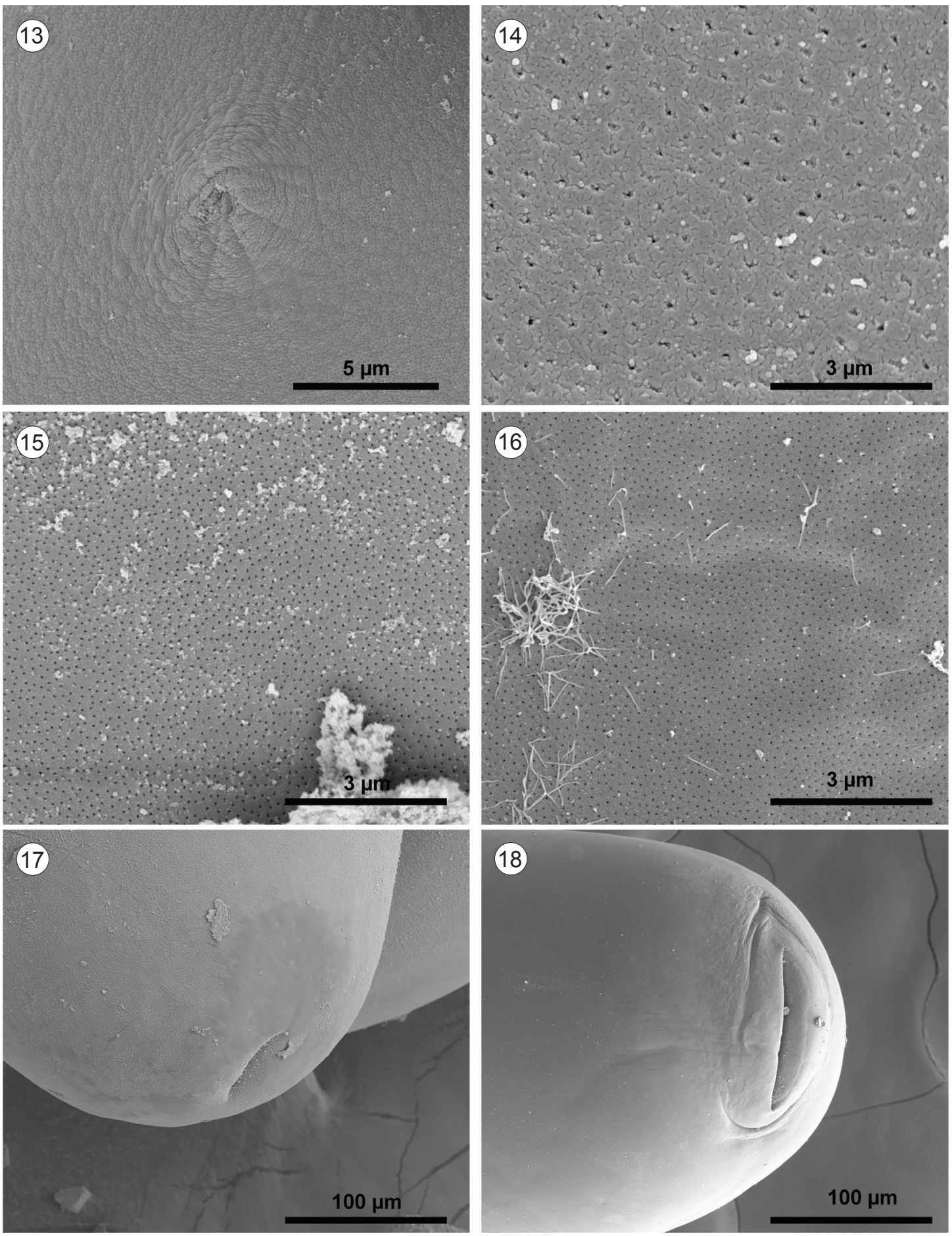

Figs. 13-18. SEM micrographs of adults of Moniliformis saudi sp. n. from the desert hedgehog, Paraechinus aethiopicus (Ehrenberg), in Saudi Arabia. Fig. 13. A high magnification of sensory pore set on a dome-shaped elevation of the apical part of the proboscis. Figs. 14-16. Micropores in the proboscis, anterior trunk and posterior trunk of specimens. Note the different pore diameters and distribution of these absorptive canaliculi openings. Figs. 17, 18. The position and orifice of the female gonopore.

nuclei more frequent anteriorly (Fig. 2). Many electron dense micropores throughout epidermal surface of trunk and proboscis (Figs. 14-16). Proboscis cylindrical, somewhat club-shaped anteriorly, with 2 apical eccentric sensory pores (Figs. 12,13) and 14 (rarely 13) longitudinal rows of 8 (rarely 7) rooted hooks each (Figs. 3, 4, 6, 7). Ventral hooks (Fig. 3) usually slightly to markedly longer and more robust than dorsal hooks (Fig. 4). Apical and subapical hooks longest (Fig. 10), with subapical hooks being most robust (Figs. 3, 4). Sharply curved hooks and longer stout roots identical in shape forming continuous sickle shaped structures gradually decreasing in size and robustness posteriorly. Roots not embedded in base or any modified epithelial structure (Figs. 3, 4). Neck marked. Proboscis receptacle about twice as long as proboscis, encased in spirally arranged muscle layers (Fig. 22) with 

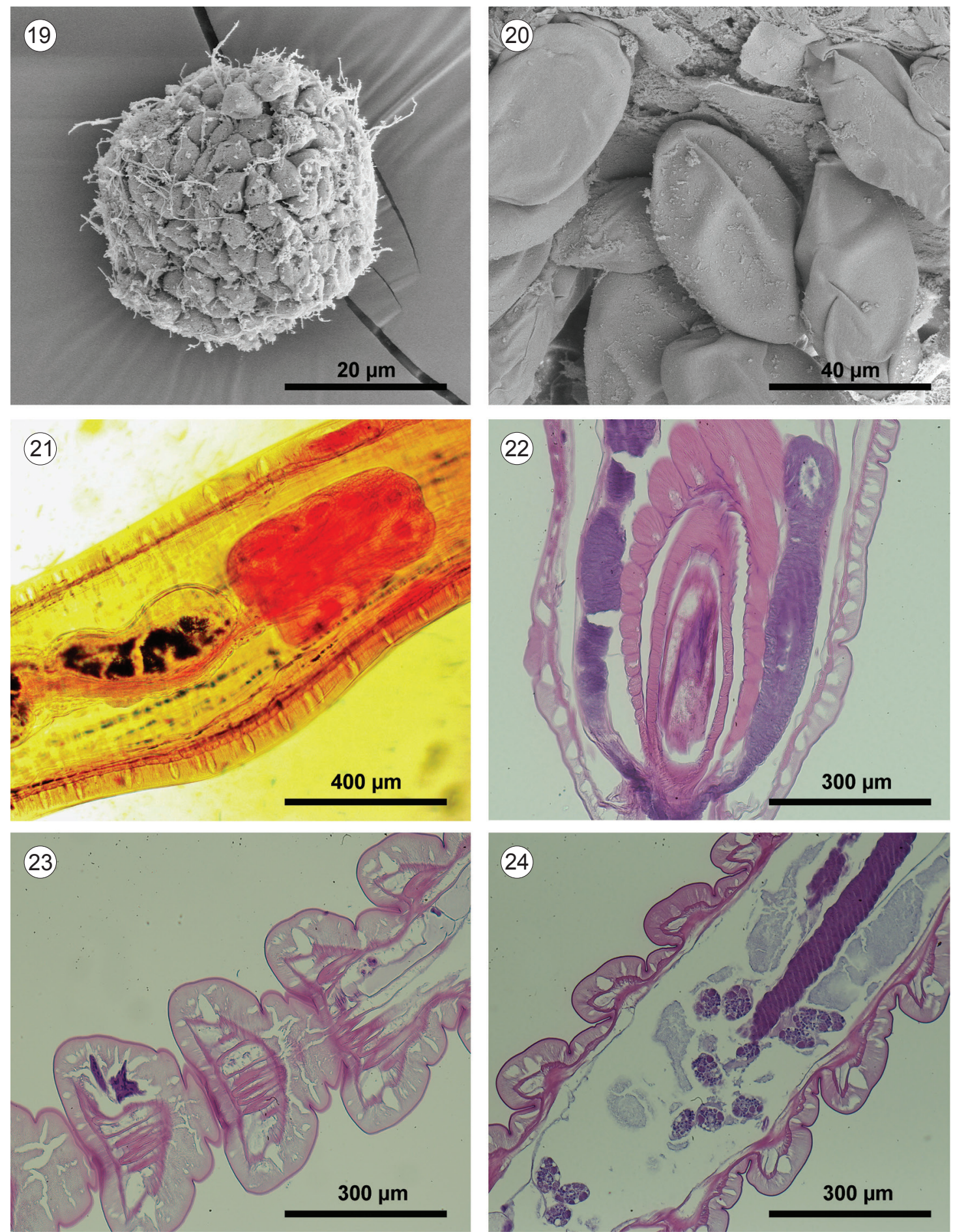

Figs. 19-24. SEM micrographs and stained whole mounts and sections of adults of Moniliformis saudi sp. n. from the desert hedgehog, Paraechinus aethiopicus (Ehrenberg), in Saudi Arabia. Fig. 19. An ovarian ball; note the filaments. Fig. 20. A cluster of eggs showing their shape and smooth surface. Fig. 21. The posterior part of a male specimen showing the cement glands and Saefftigen's pouch overlapping the cement gland and common sperm ducts. Fig. 22. A section of the anterior end of a specimen showing the oblique muscular bands enveloping the proboscis receptacle and two adjacent darker lemnisci on both sides. Figs. 23, 24. Internal appearance of pseudosegmentation in the posterior and anterior trunk of two separate specimens, respectively.

prominent ovoid cephalic ganglion at its base and posterior nucleated pouches (Fig. 6). Lemnisci relatively long, subequal, digitiform, inflated and rounded posteriorly, with 7-10 prominent nuclei in anterior half (Fig. 2). Gonopore terminal in both sexes (Figs. 2, 5); occasionally near terminal in females (Figs. 17, 18).
Males. (based on 11 mature adult males with sperm). Trunk $24-50 \mathrm{~mm}(35 \mathrm{~mm})$ long by $0.67-1.15 \mathrm{~mm}(0.94 \mathrm{~mm})$ wide. Proboscis 315-520 (396) long by 130-177 (150) wide anteriorly with 14 (rarely 13) straight rows of 8 rooted hooks each. Length of hook blades from anterior: $25-27$ (26), 25-26 (26), 25-27 (26), 22-25 (24), 20-25 (23), 


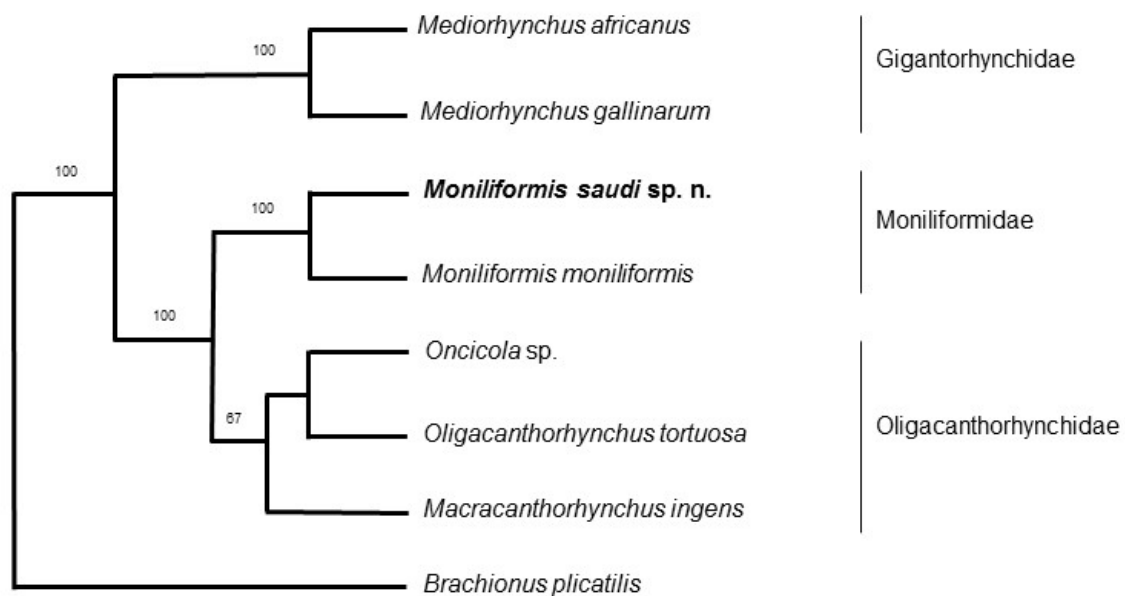

Fig. 25. Phylogeny generated using $18 \mathrm{~S}$ rDNAsequence data. Numbers at internal nodes are maximum likelihood support values. Family status within Archiacanthocephala is identified on the right.

20-21 (21), 17-21 (19), and 15-17 (16). Proboscis receptacle 603-880 (732) long by 190-300 (237) wide at outer margin of muscular layer. Shorter lemniscus $2.81-5.75 \mathrm{~mm}$ (3.94 $\mathrm{mm})$ long by $0.07-017 \mathrm{~mm}(0.11 \mathrm{~mm})$ wide posteriorly. Longer lemniscus $2.91-8.75 \mathrm{~mm}$ (4.68 mm) long by $0.08-0.17 \mathrm{~mm}(0.13 \mathrm{~mm})$ wide posteriorly. Reproductive system at posterior end of trunk. Testes oblong, close but not contiguous. Anterior testis 1.25-3.50 mm $(2.19 \mathrm{~mm})$ long by $0.27-0.82 \mathrm{~mm}(0.56 \mathrm{~mm})$ wide. Posterior testis slightly smaller, $1.12-3.50 \mathrm{~mm}(2.09 \mathrm{~mm})$ long by $0.27-0.65 \mathrm{~mm}(0.47 \mathrm{~mm})$ wide. Cement glands uninucleated, larger anteriorly, in compact cluster of 6-8, a short distance from posterior testis but adjacent to overlapping common sperm duct, cement gland duct and Saefftigen's pouch (Fig. 2). Cement glands 312-811 (563) long by 270-468 (341) wide. Saefftigen's pouch 468-1 400 (830) long by $177-450$ (290) wide.

Females. (based on 17 adult females with eggs and/ or ovarian balls). Trunk $18-117.5 \mathrm{~mm}$ (55.6 mm) long by $0.60-1.82 \mathrm{~mm}(1.18 \mathrm{~mm})$ wide at posterior half. Proboscis 354-468 (406) long by 130-208 (170) wide anteriorly, with 14 (rarely 13) straight rows of 8 (rarely 7) rooted hooks each. Length of hook blades from anterior: 25-31 (28), 22-28 (25), 22-25 (24), 20-25 (22), 17-25 (21), 15-23 (19), 15-21 (17), and 15-20 (17). Proboscis receptacle 718-1250 (987) long by 155-322 (271) wide at outer margin of muscular envelope. Shorter lemniscus $3.02-11.25 \mathrm{~mm}(7.16 \mathrm{~mm})$ long by 104-175 (160) wide posteriorly. Longer lemniscus $3.30-12.50 \mathrm{~mm}(7.78 \mathrm{~mm})$ long by 114-225 (180) wide posteriorly. Reproductive system short and compact, $1.25-1.56 \mathrm{~mm}$ (1.36 mm) long; i.e. $2.4 \%$ trunk length, with few prominent nucleated uterine glands and large robust uterine bell (Fig. 5). Ovarian balls spheroid with filaments (Fig. 19). Developed eggs ovoid, smooth, unsculptured (Figs. 1, 20), 57-83 (67) long by 31-42 (34) in diameter.

Type host: Desert hedgehog, Paraechinus aethiopicus (Ehrenberg) (Erinaceidae)

Site of infection: Small intestine.

Type 1 o cality: Central Saudi Arabia at Unaizah $\left(26^{\circ} 5^{\prime} 2^{\prime \prime N}\right.$;
4359'38"E), Al Qassim Province.

Type materia 1: Deposited in the Harold W. Manter Laboratory (HWML), University of Nebraska State Museum, Lincoln, Nebraska, USA, Coll. Nos.101645 (holotype male), 101646 (allotype female), 101647 (paratype males), 101648 (paratype females), and at the Helminthological Collection of the Institute of Parasitology, Biology Centre of the Czech Academy of Sciences, České Budějovice, Czech Republic (IPCAS Coll. No. A-90 - paratype female).

Prevalence and intensity: About 90 parasites were collected from 30 out of 89 examined individuals (prevalence $34 \%$, mean intensity 3 worms per infected animal).

Ety mology: The new species takes the name of the country of Saudi Arabia where it is found.

Remarks. The new moniliformid species is distinguished from all other species of Moniliformis by a combination of a number of morphological and molecular characters including the very small size proboscis, which has two apical sensory pores and the small size proboscis hooks that are largest anteriorly and dorsoventrally differentiated. The trunk tapers into a cone-shaped anterior with a collar of vertical segments. The eggs are also characteristically small and the female reproductive system is exceptionally short and robust. The following key (see below) further elaborates on these distinctions compared to features of all other species of Moniliformis.

\section{Molecular characterisation}

The phylogenetic status of $M$. saudi was examined using both a partial ( $664 \mathrm{bp}$ ) mitochondrial protein gene sequence, cytochrome oxidase subunit I ( $\operatorname{cox} 1)$, and a partial (1 685 bp) nuclear encoded 18S rRNA gene sequence. Each of the six $M$. saudi individuals sampled ( 3 males and 3 females) for DNA sequencing were identical in both genes. The cox 1 sequence was predicted to encode for a cox 1 polypeptide ruling out the possibility that the $\operatorname{cox} 1$ sequence originated from nucleus-located mitochondrial genes. The predicted cox 1 amino acid sequence of $M$. saudi was most closely related to $M$. moniliformis but only at $79 \%$ identity with 45/223 amino acid differences. The majority of amino 
acid differences, $33 / 45$, occur as chemically equivalent hydrophobic amino acid substitutions in the transmembrane regions of cox 1 . The sequence identity of the $18 \mathrm{~S}$ rRNA genes of $M$. saudi and M. moniliformis is $97 \%$.

The 18S rDNA, coxl and the combined 18S rDNA + cox 1 data sets were congruent with identical nodal structure and topology for both ML and MP tree reconstructions and only the $18 \mathrm{~S}$ rDNA data are shown. The best maximum-likelihood tree for the $18 \mathrm{~S}$ rDNA data (Fig. 25) had a log-likelihood score of -2243.3312. Moniliformis saudi is located in the monophyletic Moniliformidae clade sister to the only other available Moniliformis species, M. moniliformis. Moniliformidae is sister to Oligacanthorhynchidae. The order of genera within the Oligacanthorhynchidae is not well resolved (ML bootstrap value of 67) but the members of the family always are sister to Moniliformidae regardless of additional taxa added or removed. Within Archiacanthocephala, Gigantorhyhchidae are basal to Moniliformidae and Oligacanthorhynchidae.

\section{A survey of species of Moniliformis recognised as valid}

Species of Moniliformis infect warm-blooded vertebrates, mostly mammals and occasionally birds. Moniliformis saudi sp. n. is the fifteenth valid species of Moniliformis and the third known from hedgehogs. Specimens identified as $M$. moniliformis in $P$. aethiopicus were also found in Algeria. Petrochenko (1958) provided a key for 14 species and subspecies of Moniliformis of which two were relegated to other genera. The latest descriptions in Petrochenko's list were all in 1933 (Meyer 1933). Fifty five years later, Deveaux et al. (1988) added two new species bringing the number of species to 14 . Twenty eight years later, we add the $15^{\text {th }}$ species in this report. Amin (2013) listed 18 species of Moniliformis of which 4 species are not included in the following key. The remaining 14 species are considered valid (for synonyms, see Amin 2013):

Moniliformis acomysi Ward et Nelson, 1967

Moniliformis aegyptiacus Meyer, 1932

Moniliformis cestodiformis (von Linstow, 1904)

Travassos, 1917

Moniliformis clarki (Ward, 1917) Chandler, 1921 (nec Van Cleave, 1924)

Moniliformis convolutus Meyer, 1932

Moniliformis echinosorexi Deveaux, Schmidt et Krishnasamy, 1988

Moniliformis gracilis (Rudolphi, 1819) Meyer, 1931

Moniliformis kalahariensis Meyer, 1931

Moniliformis moniliformis (Bremser, 1811) Travassos, 1915 (type species)

Moniliformis monoechinus (von Linstow, 1902) Petrochenko, 1958 (nec monechinus)

Moniliformis siciliensis Meyer, 1932

Moniliformis spiralis Subrahmanian, 1927

Moniliformis tarsii Deveaux, Schmidt et Krishnasamy, 1988

Moniliformis travassosi Meyer, 1932
The five species excluded from the key are (1) Moniliformis myoxi (Galli-Valerio, 1929) (incertae sedis) [syn. Echinorhynchus myoxi Galli-Valerio, 1929], (2) Moniliformis soricis (Rudolphi, 1819) (incertae sedis) [syns. Echinorhynchus soricis Rudolphi, 1819; E. appendiculatus Westrumb, 1821], (3) Moniliformis monechinus (von Linstow, 1902) Petrochenko, 1958 nomen nudum [syn. Echinorhynchus monechinus von Linstow, 1902] as listed in Petrochenko (1958) and (4) Moniliformis merionis Golvan et Théodoridès, 1960 (incertae sedis). This species, listed as Moniliformis merionis Golvan in litt in Golvan and Théodoridès (1960), is unrecognisable as it was only described from eggs $(80 \times 40 \mu \mathrm{m})$ collected from the faeces of four species of gerbils of the genus Meriones Illiger. Infecting beetles (Coleoptera) with eggs provided uninformative descriptions of larval stages but no adult worms were found or described. (5) A fifth species not listed in Amin (2013) that is also not included in the key is Moniliformis erinacei Southwell et Macfie, 1925 because of apparent synonymy with $M$. cestodiformis where only one male and one female specimen were described from the European hedgehog, Erinaceus europaeus, from Accra, West Africa. The morphology (except for the length of lemnisci), geography and host species are the same as those of $M$. cestodiformis.

\section{Key to valid species of Moniliformis}

1 In birds. Small worms, 2.25-3.00 mm long. Proboscis with 10 rows each with $8-9$ hooks largest anteriorly. Ganglion at base of short receptacle, $360 \mu \mathrm{m}$ long. In Coracias garrullus Linnaeus (European roller) in Europe. M. gracilis

- In mammals. Longer worms with different hook formula and longer receptacle with no ganglion at base ....... 2

2 In primates. Trunk unsegmented. Proboscis 490-560 $\mu \mathrm{m}$ $\times 230-350 \mu \mathrm{m}$ with $11-12$ rows each with 6-7 hooks. Intermediate hooks considerably larger than others. Eggs very small, 47-55 $\mu \mathrm{m} \times 16-21 \mu \mathrm{m}$. In Tarsius bancanus (Horsfield), 1821 (Horsfield's tarsier) in Malaysia M. tarsi

- In other mammals. Trunk usually segmented, at least in part. Proboscis size different. Intermediate hooks not distinctly larger than others. Eggs larger 3

3 In bats. Proboscis $500 \mu \mathrm{m} \times 200 \mu \mathrm{m}$ with 12 rows of 11-12 hooks each. Posterior hooks rootless. Receptacle $700 \mu \mathrm{m}$ long. In Pteropus vampyrus Linnaeus (flying fox) in Brazil M. convolutus

- In other mammals. Proboscis, hooks and receptacle different 4

4 In hedgedog …..................................................... 5

- In other mammals ..................................................... 7

5 Proboscis $728-780 \mu \mathrm{m} \times 333-374 \mu \mathrm{m}$ with two apical sensory pores and 16 rows of $10(9-11)$ hooks each. Hooks with lateral slits in adults. Largest anterior root- 
ed hooks 45-65 $\mu \mathrm{m}$ long, largest rootless posterior spines 60-72 $\mu \mathrm{m}$ long. Eggs 73-114 $\mu \mathrm{m} \times 31-62 \mu \mathrm{m}$. In Atelerix frontalis Smith (South African hedgehog) and Pterocles namaqua Gmelin (Namaqua sandgrouse) in South Africa and Botswana ........ M. kalahariensis

- Proboscis smaller with or without apical pores. Hooks smaller and fewer without lateral slits. Eggs smaller..

6

6 Proboscis $400-500 \mu \mathrm{m} \times 200 \mu \mathrm{m}$ with $16-18$ rows of 7-8 hooks each and no apical pores. Largest hooks 30-32 $\mu \mathrm{m}$ long anteriorly; no dorsoventral differences. Eggs 85-92 $\mu \mathrm{m} \times 49-51 \mu \mathrm{m}$. Anterior trunk not modified. In Erinaceus spp. (European hedgehogs) in West Africa M. cestodiformis

- Proboscis 315-520 $\mu \mathrm{m} \times 130-208 \mu \mathrm{m}$ with apical pores and usually 14 rows of 8 hooks each. Largest hooks 25-31 $\mu \mathrm{m}$ long anteriorly. Ventral hooks longer than dorsal hooks. Eggs smaller, 57-83 $\mu \mathrm{m} \times 31-42 \mu \mathrm{m}$. Anterior trunk tapering fan-shaped with collar of vertical plates. In Paraechinus aethiopicus (desert hedgehog) in Saudi Arabia M. saudi sp. n.

7 In ant eaters. Proboscis very long, $3.55 \mathrm{~mm} \times 0.71 \mathrm{~mm}$, with many hooks, 12 rows of 40 hooks each. Largest hooks $130 \mu \mathrm{m}$ long anteriorly and shorter, $30 \mu \mathrm{m}$ long, posteriorly. In Myrmecophaga tridactyla Linnaeus (southern anteater) in South America M. monoechinus

- In rodents or Eulipotyphla. Proboscis much smaller with fewer and smaller hooks 8

8 Worms relatively long, males $95-98 \mathrm{~mm}$ and females 126-192 mm long. Proboscis relatively large, 690-1 $000 \mu \mathrm{m}$ long with $12-15$ rows of $11-13$ hooks each. Posterior hooks rootless. Receptacle large, $1.2 \mathrm{~mm}$ long in males and $2.0 \mathrm{~mm}$ long in females. Testes large, 5.6-6.8 mm long. Lemnisci long, $16.6 \mathrm{~mm}$ long with 3 giant nuclei each. In Echinosorex gymnurus Raffles (moon rat) in Malaysia. May also infect hedgehogs ................................................ M. echinosorex

- Shorter worms with smaller proboscis and fewer hooks. Receptacle, testes and lemnisci smaller 9

9 Proboscis with 14 rows of 15 hooks each. Largest hooks 24-28 $\mu \mathrm{m}$ long, tapering at both ends. Testes 2.5-3.0 mm long. Cement glands very small and eggs large, $124-127 \mu \mathrm{m} \times 71-74 \mu \mathrm{m}$. In Rattus norvegicus Berkenhout (brown rat) in Brazil ......... M. travassosi

- Proboscis with 6-13 hooks per row. Size of hooks and testes different. Cement glands larger and eggs smaller

10 Proboscis $210-450 \mu \mathrm{m} \times 120-190 \mu \mathrm{m}$ with 12 rows of $10-13$ hooks each. Hooks of equal length of 17-18 $\mu \mathrm{m}$. Eggs 84-92 $\mu \mathrm{m} \times 35-46 \mu \mathrm{m}$. In Nesokia (= Bandicota) bengalensis (Lesser) (bandicoot rat) in Burma .... M. spiralis
- Proboscis with 6-10 hooks per row. Hooks usually larger anteriorly. Eggs variable 11

11 Trunk small, males 40-45 mm long, females 70-80 mm long. Proboscis 425-450 $\mu \mathrm{m} \times 176-190 \mu \mathrm{m}$ with 14 rows of 8 hooks each, diminishing posteriorly. Lemnisci $10 \mathrm{~mm}$ long. Eggs $85 \mu \mathrm{m} \times 45 \mu \mathrm{m}$. In Rattus norvegicus (brown rat) and Eliomys quercinus Linnaeus (garden dormouse) in Sicily M. siciliensis

- Trunk longer except in M. acomysi. Proboscis $300-640 \mu \mathrm{m} \times 106-210 \mu \mathrm{m}$ with $11-16$ rows of 6-14 hooks each. Lemnisci shorter. Eggs 60-120 $\mu \mathrm{m}$ long. 12

12 Proboscis 320-640 $\mu \mathrm{m} \times 130-210 \mu \mathrm{m}$ with 11-14 (12) rows of 9-14 (10-11) hooks each. Largest hooks anterior, 19-34 $\mu \mathrm{m}$ long. Receptacle 890-1070 $\mu \mathrm{m}$ long. Testes 2.2-3.0 $\mu \mathrm{m}$ long. Eggs 84-120 $\mu \mathrm{m} \times 34-60 \mu \mathrm{m}$. In Rattus spp. and many other mammals including humans worldwide M. moniliformis

- Proboscis smaller 190-420 $\mu \mathrm{m} \times 106-210 \mu \mathrm{m}$ with 12-16 rows of fewer hooks, 6-10 per row. Largest hooks anterior or at middle, 16-31 $\mu \mathrm{m}$ long. Receptacle smaller, 680-840 $\mu \mathrm{m}$ long. Testes $1.82-3.0 \mathrm{~mm}$ long. Eggs smaller, 60-105 $\mu \mathrm{m} \times 24-52 \mu \mathrm{m}$ 13

13 Females $115 \mathrm{~mm}$ long. Segmentation faint. Proboscis $350 \mu \mathrm{m} \times 166-180 \mu \mathrm{m}$ with 12 rows of 8 hooks each. Anterior 3 hooks largest and rooted. Posterior 5 hooks rootless. Receptacle $750 \mu \mathrm{m}$ long. Eggs 95-105 $\mu \mathrm{m} \times$ 46-50 $\mu \mathrm{m}$. In Meriones sinaiticus (Sinai gerbil), Allactaga tetradactyla Lichtenstein (four-toed jerboa), Erinaceus algiris Wagner (African pigmy hedgehog) in Egypt and Alge ............................... M. aegyptiacus

- Females 12-400 mm long. Segmentation evident. Proboscis $190-420 \mu \mathrm{m} \times 120-210 \mu \mathrm{m}$ with $11-16$ rows of 6-10 hooks each. Anterior or middle hooks largest. Receptacle 670-840 $\mu \mathrm{m}$ long. Eggs 60-96 $\mu \mathrm{m} \times$ 24-52 $\mu \mathrm{m}$ 14

14 Females long, 100-130 mm. Proboscis 280-420 $\mu \mathrm{m}$ $\times 106-120 \mu \mathrm{m}$ with $12-16$ rows of $6-8$ hooks each; largest at middle. Receptacle $670-840 \mu \mathrm{m}$ long. Testes $3 \mathrm{~mm}$ long. Eggs 60-90 $\mu \mathrm{m} \times 24-36 \mu \mathrm{m}$. In squirrels, Chipmunks, deer mice, gophers in North America .... M. clarki

- Females considerably shorter, 12-76 mm long. Proboscis 190-360 $\mu \mathrm{m} \times 110-210 \mu \mathrm{m}$ with 11-16 (12-14) rows of 6-10 hooks each; largest hooks anterior. Receptacle $680-840 \mu \mathrm{m}$ long. Testes 1.82-2.31 $\mu \mathrm{m}$ long. Eggs 70-96 $\mu \mathrm{m} \times 30-52 \mu \mathrm{m}$. In Acomys cahirinus (Cairo spiny mouse) in Egypt M. acomysi

There are minor cross host infections noted in 4 acanthocephalan species. Moniliformis kalaharienses, a parasite of hedgehogs, also infects sand grouse, M. moniliformis, a parasite of rodents and other mammals, also infects hu- 

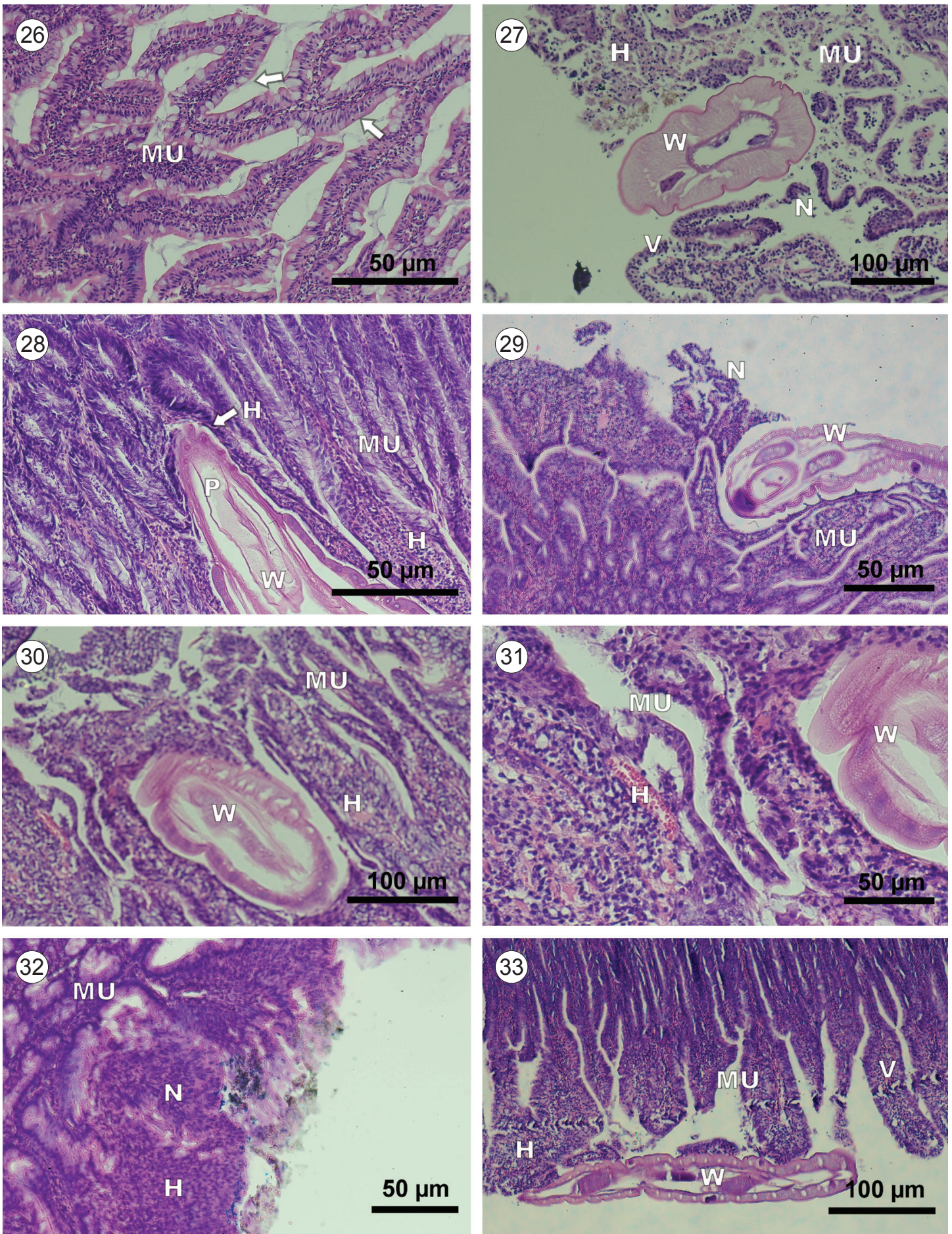

Figs. 26-33. Histopathology of specimens of Moniliformis saudi sp. n. in the intestine of Paraechinus aethiopicus (Ehrenberg). Fig. 26. Normal host intestinal tissue showing vascular mucosa with well-developed columnar epithelial cells (arrows) lining the villi and including goblet cells. Fig. 27. A specimen invading the host mucosa compressing the villi and causing necrosis of epithelial lining and hemorrhaging. Fig. 28. The worm penetrating host mucosa with the hook (arrow) around proboscis resulting in blood loss (lower right) due to damaged capillaries. Fig. 29. An acanthocephalan compressing and penetrating the villi of the host mucosa causing necrotic tissue and hemorrhaging surrounding the worm. Fig. 30. The acanthocephalan has extended into the lower reaches of the mucosa with subsequent hemorrhaging of capillary beds and tissue necrosis. Fig. 31. Higher magnification of Fig. 30. Worm penetrating the intestinal mucosa damaging villi and causing blood loss and necrosis. Fig. 32. The damaged mucosa created by the invading worm causing extensive necrosis and hemorrhaging. Note remnants of connective tissue from the intestinal villi. Fig. 33. Compression on the host villi within the intestinal mucosa due to the presence of a worm. Note extensive hemorrhaging on the left side of the invading specimen. Abbreviations: $\mathrm{H}$ - hemorrhaging; $\mathrm{MU}$ - mucosa; $\mathrm{N}$ - necrosis; $\mathrm{P}$ - proboscis; V - villi; $\mathrm{W}$ - worm. 
mans, M. aegyptiacus, a parasite of gerbils, and M. echinosorex, a parasite of moon rats, may also infect hedgehogs.

\section{Histopathology}

The normal multi-layered intestine of $P$. aethiopicus show the epithelial lined villi of the mucosa (Fig. 26). The worm gains access into the host mucosal layers utilising a hook invested proboscis (Figs. 27, 28) displacing the villi of the mucosa. Due to worm penetration, there is extensive hemorrhaging due to destruction of capillary beds. The subsequent tissue necrosis is depicted by Fig. 29. The worm continues to migrate into the host intestinal tissue (Figs. 28, 29). The penetration causes damage to the host tissue with resultant blood loss and tissue necrosis. The host intestinal villi are displaced and damaged reducing the absorptive capability of the animal's intestine. Figs. 30 and 30 show worms in the host smooth muscle layer (muscularis externa) resulting in loss of tissue components of the mucosa. Pools of blood near the worm due to the disruption of capillary beds were also noted. Migrating macrophages and other white blood cells are present for engulfing dead tissue and foreign bodies. The resultant damage to the host intestine is represented by Fig. 32 which shows extensive hemorrhaging and necrosis. Fig. 33 shows the worm attached to the mucosal surface blocking that area for absorption. Specimens of M. saudi cause extensive localised damage to the host intestine.

\section{DISCUSSION}

The desert hedgehog Paraechinus aethiopicus is one of the smallest hedgehogs and appears to be reasonably tolerant to habitat modifications. It is widely distributed in the Middle East (Egypt, Iran, Iraq, Israel, Jordan, Kuwait, Oman, Saudi Arabia, Syria, United Arab Emirates, Yemen) and north, east, and west Africa (Algeria, Chad, Djibouti, Egypt, Eritrea, Ethiopia, Libya, Mali, Mauritania, Morocco, Niger, Sahara Desert, Somalia, Sudan, Tunisia). It primarily feeds on insects and other invertebrates, but sometimes consumes eggs, small vertebrates and vegetation (Harrison and Bates 1991). The diet of the desert hedgehog in Algeria was constituted mostly of ants (Hymenoptera) but also included Gastropoda and Arachnida (Khaldi et al. 2013). The intermediate hosts of other species of Moniliformis included mostly cockroaches but also comprised other insect groups (see Schmidt 1985).

The desert hedgehog, in the type locality of the new acanthocephalan Unaizah in Central Saudi Arabia, was rather moderately infected with specimens of $M$. saudi as well as with nematodes and tapeworms. It is under these geographical and climatic conditions that the life cycle of $M$. saudi in the desert hedgehogs appear to be well maintained.

The observed molecular uniformity (six individuals from six hedgehogs with the same coxl and 18S rDNA sequence) of this albeit limited sample is consistent with a single geographic and host defined lineage of $M$. saudi. Nothing was known about the parasitic fauna of $P$. aethiopicus elsewhere in Saudi Arabia and very little is known elsewhere in the Middle East. For example, only Moniliformis moniliformis was reported from the same host species in Egypt (Nelson and Ward 1966).

The species status of $M$. saudi suggested by geographic isolation and displayed by morphological characters was further confirmed by molecular characters. As with all mitochondrial genes, the coxl gene showed a higher incidence of sequence differences compared to sister taxa than did the nuclear encoded 18S rRNA gene. The rate of mitochondrial DNA evolution due to the accumulation of spontaneous mutations is about 10 times faster than nuclear DNA (Brown et al. 1979). Both the coxl and 18S rRNA gene products are required components of essential cellular machinery and are subject to selection. Thus, most changes in the amino acid sequence of the cox 1 protein were due to substitutions of chemically synonymous amino acids.

The third position of codons in the coxl genes of the sampled Archiacanthocephala showed mutational saturation, an expected observation due to codon degeneracy. The rate of change associated with $18 \mathrm{~S}$ rDNA diversity between species is a function not only of spontaneous mutations passing through the filter of selection, but also, an outcome of partial or complete gene conversion driving concerted evolution (Ohta 1980). The further elucidation of the molecular parameters governing or uncovering the evolutionary history of Archiacanthocephala will proceed with the accumulation of a wider collection of gene sequences and whole genomes from across the class.

The penetrative properties of specimens of $M$. saudi in the intestinal lining of $P$. aethiopicus are well represented by a series of prepared glass slides (105 viewed) of the infected tissue. Where the acanthocephalans had invaded the mucosal lining of the host with well-armed proboscides, there was prominent blood loss due to capillary damage with subsequent hemorrhaging and necrosis. The worm, due to its size, can also obstruct the absorbing surface of the host intestine causing loss of essential food. The sections demonstrate the damage caused by the invading worms depicting classic tissue pathology. Due to the action of the proboscis hooks, worms can penetrate the deeper layers of the intestine including the muscularis externa with possible exit through the outer epithelial lining into the abdominal cavity. There is no evidence of encapsulation of the worm by the host as it migrates through the tissue.

Acknowledgements. This work was supported by funding from the King Saud University, Vice Deanship of Research Chairs, by the Department of Microbiology and Molecular Biology, Brigham Young University (BYU), Provo, Utah and by an Institutional Grant from the Parasitology Center, Inc., Scottsdale, Arizona. Thanks are due to the Histology Laboratory, Utah Valley Regional Medical Center, Mike Downey Director, for the histopathology slide preparation. We are also grateful to Michael Standing and Stephen Hunsaker, BYU Electron Optics Center and Beans Museum, respectively, for their professional help with electron optics equipment and plate preparation and editing. We are especially grateful to Abdulaziz Alagaili, Department of Zoology, College of Science, King Saud, University, Riyadh, Saudi Arabia, for making resource material available for this study. 


\section{REFERENCES}

Amin O.M. 2013: Classification of the Acanthocephala. Folia Parasitol. 60: 273-305.

Bancroft J.D., Gamble M. 2001: Theory and Practice of Histological Techniques. Fifth Edition. Churchill Livingston, Edinburgh, $800 \mathrm{pp}$.

Brown W.M., George M. JR., Wilson A.C. 1979: Rapid evolution of animal mitochondrial DNA. Proc. Nat. Acad. Sci. USA 76: 1967-1971.

Deveaux T.P., Schmidt G.D., Krishnasamy M. 1988: Two new species of Moniliformis (Acanthocephala: Moniliformidae) from Malaysia. J. Parasitol. 74: 322-325.

Folmer O., Black M., Hoeh W., Lutz R., Vrijenhoek R. 1994: DNA primers for amplification of mitochondrial cytochrome $c$ oxidase subunit I from diverse metazoan invertebrates. Mol. Mar. Biol. Biotechnol. 3: 294-299.

Galigher A.E., Kozloff E.N. 1971: Essentials of Practical Microtechnique, Second Edition. Lee \& Febiger, Philadelphia, 531 pp.

Golvan Y.J., ThÉodoridès J. 1960: Cycle évolutif d'un acanthocéphale parasite de Gerbillidés du genre Meriones en Iran. C. R. Séanc. Acad. Sci. Paris. 250: 224-225.

Guindon S., Gascuel O. 2003: A simple, fast, and accurate algorithm to estimate large phylogenies by maximum likelihood. Syst. Biol. 52: 696-704.

Harrison D., Bates P.J. 1991: The Mammals of Arabia. Second Edition. Harrison Zoological Museum Publ., Sevenoaks, 354 pp.

Joвв G. 2008: TREEFINDER version of October 2008. Munich. Distributed by the author at www.treefinder.de

Kearse M., Moir R., Wilson A., Stones-Havas S., Cheung M., Sturrock S., Buxton S., Cooper A., Markowitz S., Duran C., Thierer T., Ashton B., Meinties P., Drummond A. 2012: Geneious Basic: an integrated and extendable desktop software platform for the organisation and analysis of sequence data. Bioinformatics 28: 1647-1649.

Khaldi M., Torres J., Samso B., Miquel J., Biche M., Benyettou M., Barech G., Benelkadi H.A., Ribas A. 2012: Endoparasites (helminths and coccidians) in the hedgehogs Atelerix algirus and Paraechinus aethiopicus from Algeria. Afr. Zool. 47: 48-54.

KiERnAN J.A. 2002: Histological and Histochemical Methods: Theory and Practice. Churchill Livingston, Edingburgh, 520 pp.

LeE R.E. 1992: Scanning Electron Microscopy and X-Ray Microanalysis. Englewood Cliffs, Prentice Hall, New Jersey, 458 pp.

Meyer A. 1933: Acanthocephala. Dr. H.G. Bronn's Klassen und Ordnungen des TierReichs. Akad. Verlag., Leipzig. 4: 333-582.

Near T.J., Garey J.R., NAdLer S.A. 1998: Phylogenetic relationships of the Acanthocephala inferred from 18S ribosomal DNA sequences. Mol. Phylogen. Evol. 10: 287-298.

Nelson D.R., Ward H.L. 1966: Acanthocephala from hedgehogs in Egypt. J. Tenn. Acad. Sci. 37: 101-105.

Онта, T. 1980: Evolution and variation of multigene families. Vol. 37. Germany, Springer-Verlag, Berlin, $135 \mathrm{pp}$.

Petrochenko V.I. 1958: Acanthocephala of Domestic and Wild Animals. Izdatel'stvo Akad. Nauk SSSR. Moscow (English translation by Israel Program for Scientific Translations, Jerusalem, 1971), $478 \mathrm{pp}$.

Posada D. 2008: jModelTest: Phylogenetic Model Averaging. Mol. Biol. Evol. 25: 1253-1256.

Schmidt, G.D. 1985: Development and life cycles. In: D.W.T. Crompton and B.B. Nickol (Eds.), Biology of the Acanthocephala. Cambridge Univ. Press, Cambridge, pp. 273-305.

Swofford D. L. 2003: PAUP* Phylogenetic Analysis Using Parsimony (*and Other Methods). Version 4. Sinauer Associates, Sunderland, Massachusetts.

Cite this article as: Amin O.M., Heckmann R.A., Mohammed O., Evans R.P. 2016: Morphological and molecular descriptions of Moniliformis saudi sp. n. (Acanthocephala: Moniliformidae) from the desert hedgehog, Paraechinus aethiopicus (Ehrenberg) in Saudi Arabia, with a key to species and notes on histopathology. Folia Parasitol. 63: 014. 